\title{
Modeling, prediction and multi-objective optimization of the coal gasification system
}

\author{
Ran $\mathrm{Li}^{1}$, Zhen Yang ${ }^{1, *}$, and Yuanyuan Duan ${ }^{1}$ \\ ${ }^{1}$ Key Laboratory for Thermal Science and Power Engineering of MOE, Beijing Key Laboratory for $\mathrm{CO}_{2}$ Utilization and Reduction \\ Technology, Tsinghua University, Beijing, 100084, PR China
}

\begin{abstract}
As global energy demand continues to increase, coal as basic energy still accounts for a significant proportion. Under the pressure of environmental protection, clean and efficient coal utilization technologies are in great demand. Coal gasification technology has the potential to realize near-zeroemissions for coal utilization. This paper establishes the coal gasification system model and analyzes the effect of oxygen/coal ratio and water/coal ratio on the system performance index of cold syngas efficiency, effective component ratio, carbon conversion ratio, and production ratio of hydrogen. The results show that when the oxygen/coal ratio increases, the efficiency of cold syngas and effective components ratio increase first and then decrease, carbon conversion ratio first increases and then remains unchanged, hydrogen production ratio gradually decreases; When the steam/coal ratio increases, the cold syngas efficiency, and carbon conversion ratio first increase and then decrease, effective component ratio ingredients gradually decreases, and the hydrogen production ratio increases. Using BP neural network to realize the prediction of the gasification system, and the mean square error reaches the magnitude of 10e-7. Multi-objective optimization results show that the oxygen/coal ratio and steam/coal ratio corresponding to the highest production ratio of hydrogen is 0.52 and 0.05 . The highest carbon conversion ratio corresponds to the oxygen/coal ratio of 0.95 and the steam/coal ratio of 0.05 .
\end{abstract}

\section{Introduction}

With the increasing pressure on environmental protection, carbon emissions have become the focus of attention in energy consumption. Although the proportion of renewable energy power generation is increasing year by year, coal as a primary energy source still accounts for $27 \%$ of total energy consumption ${ }^{[1]}$. In the future, clean and efficient coal utilization technology will be a severe challenge facing many countries. The results of research and practical application both show the use of coal gasification technology has certain advantages in terms of pollutant emission and energy efficiency compared with traditional coal direct combustion $^{[2-4]}$. The application of coal gasification technology in the field of power generation (Integrated gasification combined cycle, IGCC) has the potential to achieve near-zero emissions for coal power generation ${ }^{[5]}$.

Coal gasification is a complex thermochemical process. The main factors include coal type, gasification method, and gasifier operating parameters ${ }^{[6]}$. While the gasification method and coal type are selected, the main operating parameters of the gasifier include pressure, temperature, and the proportion of gasification agent. The evaluation objectives of the gasifier mainly include cold syngas efficiency, carbon conversion ratio, effective component mole ratio. Scholars have conducted a lot of related researches on the parameter analysis of the gasifier. Oh et al. ${ }^{[7]}$ simulated a entrain bed gasifier and explored the influence of gasification agent flow rate, and type on cold syngas efficiency and carbon conversion ratio, obtained the optimal cold syngas efficiency and carbon conversion ratio of $57.7 \%$ and $90.7 \%$; Su et al. ${ }^{[5]}$ used computational fluid dynamics to establish entrain-bed gasifier model, and simulated the influence of a single variable in parameters such as temperature, pressure, oxygen/coal ratio, and steam/coal ratio on the main gasification product components $(\mathrm{CO}$, $\mathrm{H}_{2}, \mathrm{CO}_{2}$ ); $\mathrm{Liu}^{[6]}$ used Aspen plus to simulate and analyze the circulating fluidized bed gasifier and obtained the effects of different operating parameters on the effective syngas content, gas heating value, and cold syngas efficiency. also, the influence weights of different parameters are obtained by the orthogonal experiment; Jang et al. ${ }^{[8]}$ established entrained bed gasifier model in Aspen plus, changed coal water slurry concentration, oxygen/coal ratio, gasification temperature, and pressure, analyzed the sensitivity of the system with the above four variables, obtained the trend of cold syngas efficiency and carbon conversion rate with the above parameters.

For power generation, the energy efficiency characteristics of the gasification process are also particularly important. However, as environmental protection requirements increase, carbon capture has become a key process, and the composition of coal

Corresponding author: zhenyang@tsinghua.edu.cn 
gasification products has also become an important parameter that affects the overall performance of the power generation system. IGCC system currently uses pre-carbon capture methods, the main principle is to use the water-gas shift reaction to convert the carbon monoxide into hydrogen, so the carbon monoxide and hydrogen of gasification products are the effective components. Considering the total cost of carbon capture, increasing the hydrogen production ratio can reduce the total cost of carbon capture while ensuring that the effective components account for a relatively high proportion. Therefore, even for power generation, IGCC power plants, the hydrogen production ratio is also an important indicator. Besides, the carbon conversion ratio is also a key factor that affects the subsequent carbon capture process.

The current researches on the influence of gasification process parameters of gasifiers focus on the influence of a single variable on a single objective, lacks multi-parameter analysis. Besides, most researchers select a single objective in the optimization and lack multi-objective optimization results. Therefore, this research mainly focuses on multi-objective optimization analysis of the coal gasification process. The obtained results have greater generalization.

For the complex thermochemical process, most scholars use third-party software (Aspen plus or Fluent et al.) to simulate the sensitivity and optimization of a single variable, and it is difficult to achieve multiobjective optimization. Among the multi-objective optimization algorithms, the genetic algorithm is a way to search for the optimal solution by simulating the natural evolution process, which is widely used in various optimization studies ${ }^{[9,10]}$. This paper uses BP neural network to connect simulation results and the genetic algorithm. The advantage of the BP neural network is that it can fit nonlinear functions. And genetic algorithm can find the global optimal solution of nonlinear functions. The combination of the two algorithms can realize multi-parameter and multiobjective optimization of the coal gasification process.

The innovation of this paper mainly include: the research methods, using the neural network to connect the simulation results and genetic algorithm to achieve optimization; In terms of research content, the gasification process is optimized with multiple objectives to obtain the optimal solution.

The research content of this paper mainly includes:

(1) Establishes a coal gasification calculation model;

(2) Uses BP neural network to establish the functional relationship between input and output parameters in the coal gasification process;

(3) Multi-objective optimization of the coal gasification process using the genetic algorithm to obtain the optimal solution.

\section{Model and mathematical method}

\subsection{Gasification model}

Firstly, the coal gasification model is established. The gasification model is shown in Fig.1, in which the corresponding model selected by each module in Aspen and the coal gasification process implemented are shown in Table 1. Among them, the gasification reaction of Block-7 is complex, and the relevant data of reaction kinetics involved are from the literature ${ }^{[11]}$. This paper uses the Illinois No.6 coal to verify the accuracy of the model, adopts the same coal and gasification process parameters as literature ${ }^{[11]}$. The comparison results are shown in Table 3. through the verification, found that the model of results has good consistency with the experimental results. Table 2 shows the coal information adopted, and Table 3 shows the model verification results.

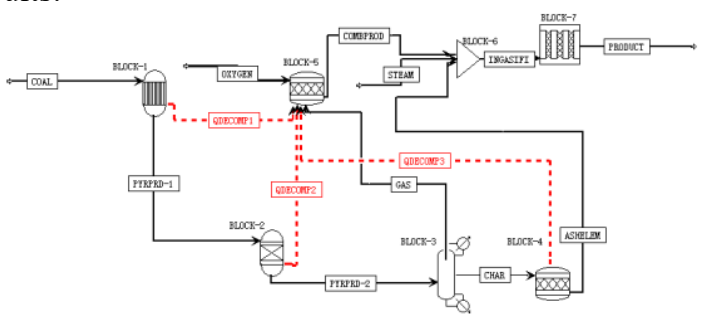

Fig. 1. Gasification simulation model.

Table 1. The selected model and the corresponding process.

\begin{tabular}{|c|c|c|}
\hline Block & Aspen plus model & Physicochemical process \\
\hline 1 & RYield & Atmospheric pyrolysis \\
\hline 2 & RYield & High-pressure pyrolysis \\
\hline 3 & Sep & Gas solid separation \\
\hline 4 & RStoic & Coke decomposition \\
\hline 5 & RStoic & Volatile combustion \\
\hline 6 & Mixer & Material mix \\
\hline 7 & Rplug & gasification reaction \\
\hline
\end{tabular}

Table 2. Properties of the feed coal

\begin{tabular}{|l|l|l|l|l|l|l|l|l|}
\hline \multicolumn{3}{|l|}{ Proximate analysis (wt.\%) } & \multicolumn{5}{|c|}{ Ultimate analysis (wt.\%) } \\
\hline MO & VA & FC & ASH & C & H & O & N & S \\
\hline 0.2 & 26.4 & 57.9 & 15.5 & 74.1 & 6.3 & 1.3 & 0.7 & 1.8 \\
\hline
\end{tabular}

Table 3. Model validation results (dry product gas)

\begin{tabular}{|l|l|l|l|}
\hline Component & $\begin{array}{l}\text { This paper } \\
(\text { mole } \\
\text { fraction/\%) }\end{array}$ & $\begin{array}{l}\text { Experiment } \\
(\text { mole } \\
\text { fraction/\%) }\end{array}$ & Error/\% \\
\hline $\mathrm{CO}$ & 57.57 & 57.82 & 0.43 \\
\hline $\mathrm{H}_{2}$ & 39.13 & 36.43 & -6.9 \\
\hline $\mathrm{CO}_{2}$ & 2.95 & 2.97 & 0.73 \\
\hline
\end{tabular}

The calculation of gasification performance objective mainly includes the cold syngas efficiency, the mole proportion of the effective component $\left(\mathrm{CO}+\mathrm{H}_{2}\right)$ ratio, and the carbon conversion ratio.

Cold syngas efficiency refers to the ratio of the total heat of syngas to the heat of the fuel used. The calculation formula ${ }^{[12]}$ is (1):

$$
\eta=\frac{[\text { mass flow } \times \text { heating value }]_{\text {syngas }}}{[\text { mass flow } \times \text { heating value }]_{\text {coal }}} \times 100 \%
$$

The effective component ratio refers to the sum of the molar fractions of $\mathrm{CO}$ and $\mathrm{H}_{2}$ in the syngas, and the calculation formula is (2): 


$$
R=\frac{\left(V_{C O}+V_{H 2}\right)}{V}
$$

$V$ is the moles of syngas, $V_{C O}$ and $V_{H_{2}}$ refer to the moles of $\mathrm{CO}$ and $\mathrm{H}_{2}$.

Carbon conversion ratio $x_{\mathrm{c}}$ refers to the carbon content of syngas to carbon in the coal ratio.

$$
x_{\mathrm{c}}=\left(1-\frac{\text { Carbon in gasification residue }}{\text { Carbon in feedstock }}\right) \times 100 \%
$$

Hydrogen production ratio refers to the proportion of hydrogen in the syngas.

\subsection{BP neural network}

BP neural network is a multi-layer neural network composed of input layer, hidden layer, and output layer. Figure 2 shows the BP neural network structure with the number of hidden layer is 1 , where $x_{n}$ represents the input parameter and $y_{n}$ represents the output parameter.

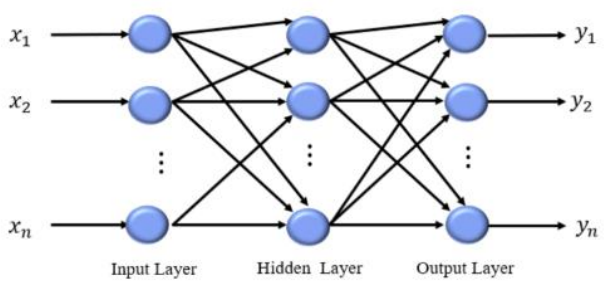

Fig. 2. Structure of BP neural network for multi-objective evaluation: the number of hidden layers is 1 .

The number of hidden layers and the number of nodes are 1 and 20 , and the learning rate is 0.01 .

\subsection{Genetic algorithm (GA)}

GA is used to solve the optimization problem of the maximum value of the function, and the mathematical programming model is shown in Equation (4).

$$
\begin{aligned}
& \max f(x) \\
& x \in R \\
& R \subset U
\end{aligned}
$$

Where $x$ is the decision variable, $\max f(x)$ is the objective function equation, $x \in R \quad R \subset U$ is the constraint condition, $U$ is the basic space, $R$ is the subset of $U$.

The calculation method adopted in this paper is to firstly build the coal gasification model in Aspen Plus, change different operation parameters, and obtain different output parameters; Secondly, BP neural network is used to establish the functional relationship between inputs and outputs; Finally, utilize the genetic algorithm to optimize the system, and the optimal operating parameters of the system are obtained. The calculation process is shown in Fig.3.

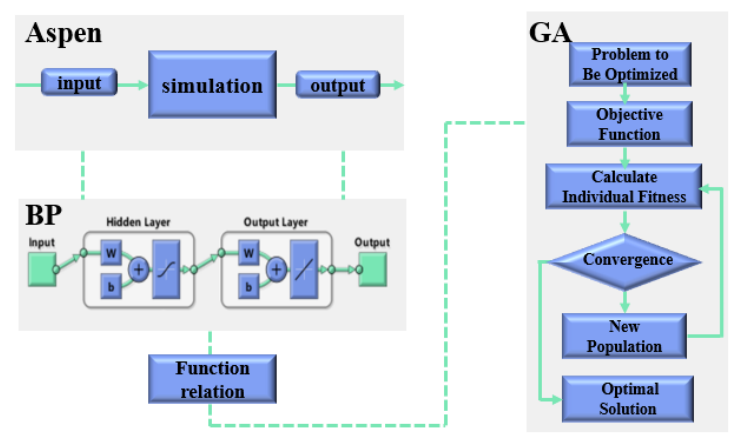

Fig. 3. Computational flow chart.

\section{Result}

The main control parameters selected in this paper are oxygen/coal ratio and steam/coal ratio. The objectives are cold syngas efficiency, effective component ratio, carbon conversion ratio, and hydrogen production ratio.

Fig.4-7 show the effects of oxygen/coal ratio and steam/coal ratio on cold syngas efficiency, effective component ratio (dry syngas), carbon conversion ratio, and hydrogen production ratio. It can be found that the influence trend of the oxygen/coal ratio on the first three performance objectives oxygen-coal ratio is that with the increase of oxygen/coal ratio, the target value first increases and then decreases, but the carbon conversion ratio first increases and then remains unchanged. The maximum achievable values of the three target parameters are $0.933,0.987,0.998$. When the steam/coal ratio is selected as 0.2 , the highest cold syngas efficiency and the ratio of effective components corresponding to oxygen/coal ratio are both 0.88 , and the highest carbon conversion ratio corresponds to oxygen/coal ratio is 0.9 . It can be seen that when the oxygen/coal ratio changes, the peak points of cold syngas efficiency, effective component ratio, and carbon conversion rate are very close. The main reason is that when the coal type is fixed, the cold syngas efficiency of the system is mainly affected by the amount of combustible substances ( $\mathrm{CO}$, $\mathrm{H}_{2}, \mathrm{CH}_{4}$, etc.) in the gasification product, so the changing trend of the cold syngas efficiency and the proportion of effective components has high consistency. When the oxygen/coal ratio takes a larger value, the reason for the declining trend of cold syngas efficiency is that the proportion of hydrogen decreases. Although the total proportion of effective ingredients does not change much, the calorific value per mole of hydrogen is slightly higher than that of carbon monoxide, resulting in cold gas efficiency drops. As the oxygen/coal ratio increases, the hydrogen production ratio decreases because the oxygen concentration is too high, which leads to carbon monoxide and coke are more likely to react with oxygen and the hydrogen production ratio decreases. 


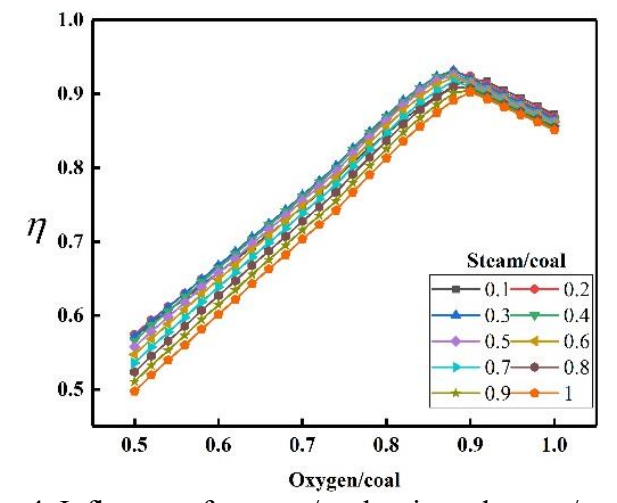

Fig. 4. Influence of oxygen/coal ratio and steam/coal ratio on cold syngas efficiency.

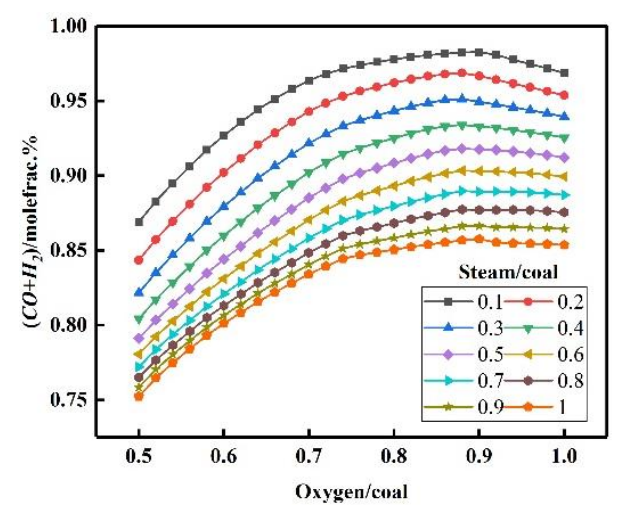

Fig. 5. Influence of oxygen/coal ratio and steam/coal ratio on the mole fraction of $\left(\mathrm{CO}+\mathrm{H}_{2}\right)$.



Fig. 6. Influence of oxygen/coal ratio and steam/coal ratio on carbon conversion ratio.

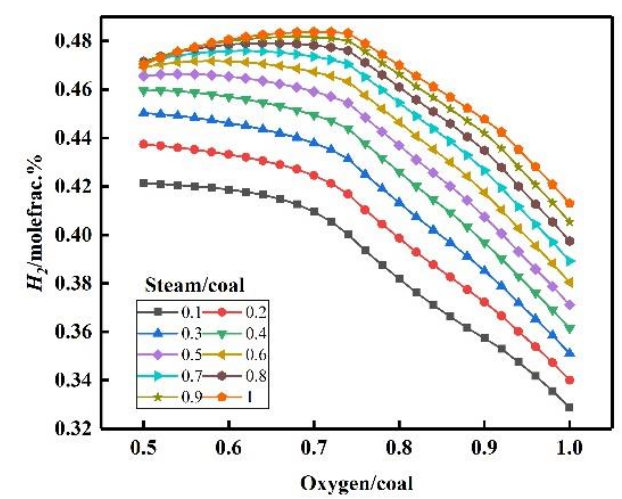

Fig. 7. Influence of oxygen/coal ratio and steam/coal ratio on the mole fraction of $\mathrm{H}_{2}$.

The effects of steam/coal ratio on the cold syngas efficiency, effective component ratio, and carbon conversion ratio are similar, which the smaller the steam/coal ratio is, the larger the target value is. As the steam/coal ratio increases, more carbon monoxide, and water react to produce carbon dioxide and hydrogen, resulting in a higher hydrogen production ratio.

As the steam/coal ratio increases, the effective component ratio decreases, because the smaller the steam/coal ratio leads to a decrease in the amount of coke that reacts with steam. This reaction is an endothermic reaction, which reduces the heat absorption, improves the overall carbon conversion rate, and makes the effective component ratio increase.

According to the calculated results, it is found that the variation trend of the three target values of cold syngas efficiency, effective component ratio, and carbon conversion ratio is relatively consistent, so carbon conversion ratio and hydrogen production ratio are selected as the two objectives in system multi-objective optimization.

According to the data calculated by the gasification model, the BP neural network is used to calculate the functional relationship between inputs and outputs. The accuracy of the training, verification, and test obtained by selecting the hidden layer as 1 and the number of intermediate nodes as 20 is shown in Fig.8. The mean square error of objectives are $2.72 \mathrm{e}-07$ and $1.47 \mathrm{e}-07$ respectively.
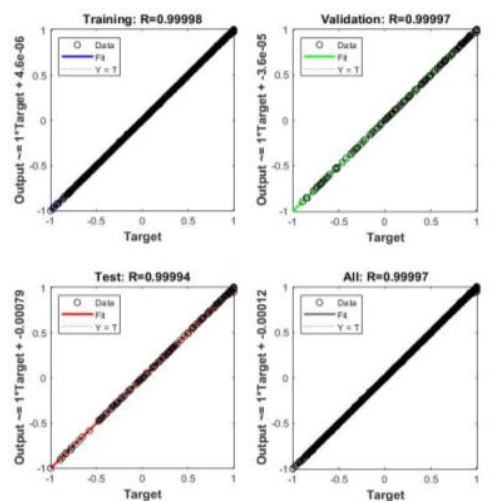

Fig. 8. The accuracy of BP neural network training, verification, and test.

The results show that BP neural network can predict the thermodynamic process accurately.

The prediction model obtained above is applied to the multi-objective genetic algorithm to realize the multi-objective optimization of the coal gasification system. The obtained system Pareto front curve is shown in Fig.9. The results show that when the optimal carbon conversion ratio is respectively small, the sacrifice of carbon conversion ratio to increase the ratio of hydrogen production is not obvious. When the carbon conversion ratio is higher than 0.75 , to achieve a higher carbon conversion rate, the hydrogen production rate decline significantly. When the carbon conversion rate is higher than 0.97 , the hydrogen production rate decline is the most obvious. Therefore, for the overall system to achieve a higher carbon conversion ratio, the greater the hydrogen production ratio that needs to be sacrificed.

And the oxygen/coal ratio and steam/coal ratio corresponding to the highest hydrogen rate are 0.52 and 0.05 respectively. The highest carbon conversion ratio 
corresponds to the oxygen/coal ratio of 0.95 and the steam/coal ratio of 0.05 .

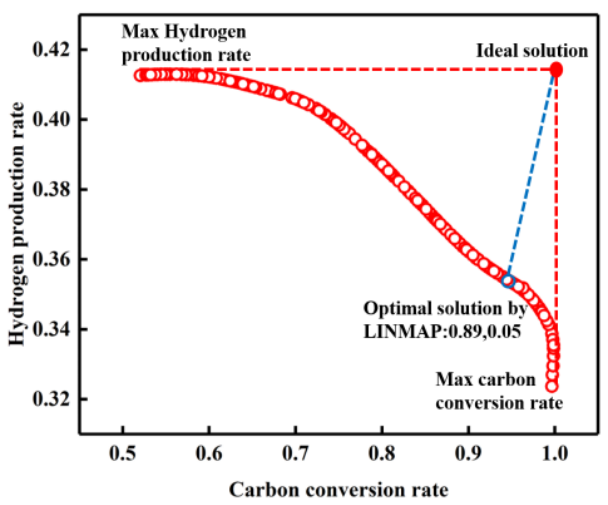

Fig. 9. Multi-objective Pareto front curve.

The optimal operation parameters of the multiobjective optimization are: oxygen/coal ratio of 0.89 and steam/coal ratio of 0.05 .

\section{Conclusion}

In this paper, the influence trend of oxygen/coal ratio and water/coal ratio on the performance of gasification system is obtained. It is calculated that the maximum cold syngas efficiency, effective component ratio, carbon conversion ratio, and hydrogen production ratio are $0.933,0.987,0.999$, and 0.483 respectively.

The BP neural network with the number of hidden layers and the number of intermediate nodes of 1 and 20 can be used to realize the output prediction of the gasification system. The mean square error of the predicted target value is $2.72 \mathrm{E}-07$ and $1.47 \mathrm{e}-07$.

The Pareto front curve is obtained by optimization of the two objectives of carbon conversion rate and hydrogen production rate. The results show that optimal operation parameters of the multi-objective optimization are: oxygen/coal ratio of 0.89 and steam/coal ratio of 0.05 .

This paper only focuses on the optimization of the gasification process, and urgently needs to solve the overall optimization of the IGCC system in the future to provide theoretical guidance for the development of clean, efficient, and low-carbon coal power generation technology. At the same time, the objective of optimization includes not only thermal performance but also economic performance.

This work was supported by National Science and Technology Major Project(J2019-I-0009).

\section{References}

1. BP, Statistical Review of World Energy. https://www.bp.com/en/global/corporate/energy- economics/statistical-review-of-world-energy.html, 2020. 4.

2. Rosner, F., Chen, Q., Rao, A., Samuelsen, S. Thermo-economic analyses of concepts for increasing carbon capture in high-methane syngas integrated gasification combined cycle power plants. Energy Conversion and Management, 2019. 199.

3. Rosner, F., Chen, Q., Rao, A., Samuelsen, S. Thermo-economic analyses of IGCC power plants employing warm gas $\mathrm{CO} 2$ separation technology. Energy, 2019. 185: 541-553.

4. Yoon, S.Y., Choi, B.S., Ahn, J.H., Kim, T.S. Improvement of integrated gasification combined cycle performance using nitrogen from the air separation unit as turbine coolant. Applied Thermal Engineering, 2019. 151: 163-175.

5. Su, L., Feng, S.D., Li, P., Zhang, Y., Liu, Z.Y., Li, Z.M. Study on Simulation of Pulverized Coal Gasification Process in the GSP Gasifier. Canadian Journal of Chemical Engineering, 2017. 95(4): 688697.

6. Liu, Z.H. Simulation and Optimization of coal gasification process in circulating fluidized bed. 2018. University of Chinese Academy of Sciences (Institute of Engineering Thermophysics, Chinese Academy of Sciences).

7. Oh, G., Ra, H.W., Yoon, S.M., Mun, T.Y., Seo, M.W., Lee, J.G., Yoon, S.J. Gasification of coal water mixture in an entrained-flow gasifier: Effect of air and oxygen mixing ratio. Applied Thermal Engineering, 2018. 129: 657-664.

8. Jang, D.H., Yoon, S.P., Kim, H.T., Choi, Y.C., Lee, C. Simulation analysis of hybrid coal gasification according to various conditions in entrained-flow gasifier. International Journal of Hydrogen Energy, 2015. 40(5): 2162-2172.

9. Punnathanam, V., Kotecha P. Effective multiobjective optimization of Stirling engine systems. Applied Thermal Engineering, 2016. 108: 261-276.

10. Hu, S.Z., Li, J., Yang F.B., Yang, Z., Duan, Y.Y. Multi-objective optimization of organic Rankine cycle using hydrofluorolefins (HFOs) based on different target preferences. Energy, 2020. 203.

11. Wen, C.Y., Chaung T.Z. Entrainment coalgasification modeling. Industrial and Engineering Chemistry Process Design and Development, 1979. 18(4): 684-695.

12. Li, R.B., Xie, M.Z., Jin, H., Guo, L.J., Liu, F.Q. Effect of swirl on gasification characteristics in an entrained-flow coal gasifier. International Journal of Chemical Reactor Engineering, 2020. 18. 